\title{
El primer papel moneda en la tradición "Una moza de rompe y raja"
}

\author{
Arnaldo Mera Ávalos \\ Pontifica Universidad Católica del Perú \\ arnaldo_mera@hotmail.com
}

\section{Resumen}

A partir de un personaje de la plebe que aparece en la tradición de Palma "Una moza de rompe y raja", abordamos un interesante aspecto de historia social y económica del régimen del Protectorado establecido por el general San Martín como fue la creación del banco de papel moneda y la aceptación del papel moneda por la población limeña.

Palabras clave: Protectorado, Historia Social, Historia Económica, Independencia, Ricardo Palma

\begin{abstract}
From a character of the plebs that appears in the tradition of Palma "Una moza de rompe y raja", we tackle an interesting aspect of social and economic history of the regime of the Protectorate established by general San Martin such as the creation of the paper bank currency and the acceptance of paper money by the Lima population.
\end{abstract}

Keywords: Protectorate, Social History, Economic History, Independence, Ricardo Palma 
Arnaldo Mera Ávalos, Licenciado en Historia por la Pontificia Universidad Católica del Perú con la tesis "Las Pulperías en Lima ante el impacto de las reformas borbónicas" (2014), y donde cursó estudios de maestría en Historia y Derecho Constitucional y bachiller en Historia y Derecho por la misma universidad. Es miembro asociado del Instituto Riva Agüero y miembro de número del Instituto Ricardo Palma. Ha publicado "Ecuador y Perú: espacios regionales siglo XIX" En: Espacio: teoría y praxis (1997); "Pulperas, chinganeras y chicheras en la Lima republicana (18301860)" En: Mujeres y género en la historia del Perú (1999); "Las armas del rey de España en sus dominios del Perú (15321824)" En: Boletín de Riva Agüero, $n^{\circ} 30$ (2003); "Cronología de Carlos A. Romero" En: Adiciones a la Imprenta en Lima de José Toribio Medina, Carlos A. Romero (2009), entre otros artículos de historia del Perú, siglos XVIII y XIX. 


\section{Introducción}

Es difícil pensar que en una tradición de don Ricardo Palma se hable de aspectos de historia económica del régimen del Protectorado, los cuales fueron escritos en 1876 y publicados en la serie IV de las Tradiciones en 1894 (Díaz Falconí, 2015: 247). Aspectos que habían sido debidamente mencionados por Mariano Felipe Paz Soldán en su Historia del Perú Independiente ocho años antes, en 1868, pero que recién serían estudiados a profundidad por el académico de la historia Carlos Camprubí y publicados a inicios de la década del sesenta del siglo XX en su obra no superada El banco de la emancipación (Camprubí, 1960), pero lo cierto es que Palma reiteró en un par de párrafos un tema de la historia económica del Perú debidamente expuesto por Paz Soldán, sazonado con la picardía típica de nuestro tradicionista, y que solo recién sería vuelto a mencionar sesenta y seis años después. Además, desde el punto de vista social, el recibimiento de este papel moneda en la ex Ciudad de los Reyes aún no ha sido abordado.

\section{Antecedentes}

Palma nos relata que:

Estando Pasco y Potosí en poder de los realistas, la casa de Moneda no tenía barras de plata que sellar, y entre los grandes políticos y financistas de la época surgió la idea salvadora de emitir papel moneda para atender a los gastos de la guerra. Cada uno estornuda como Dios lo ayuda. (Palma, 1964: 968).

$\mathrm{Al}$ respecto, en el estudio introductorio que en el 2014 realiza a la reimpresión del trabajo de Camprubí, el historiador español Dionisio de Haro Romero afirma categóricamente que: 
En el proceso de la Independencia del Perú se trataron las controversias monetarias y bancarias con enfoques modernos las medidas encaminadas a resolver los graves problemas de liquidez que venía arrastrando la economía virreinal y que se vieron agravados con la guerra de independencia (...). Desde la perspectiva monetaria la iniciativa más singular fue la representada por el banco de papel moneda. La original experiencia bancaria del Perú significó la primera iniciativa de emisión de papel moneda por parte de una autoridad pública en Sudamérica. (Camprubí, 2014: 18).

Este historiador no señala los antecedentes, como sí lo hizo en su momento Paz Soldán, quien nos dice:

En el año 1800 se sintió por primera vez en el Perú la falta de dinero circulante y continuó la escasez hasta que en 1815 la Junta de Arbitrios propuso el plan de emitir vales o sea papel moneda que todos rechazaban y cayó en completo descrédito. Con este antecedente fatal era difícil que el público recuperase la confianza que si no la tuvo en épocas normales era casi imposible que la adquiriera en circunstancias tan tormentosas. (1971: 296).

\section{El Banco de Papel Moneda}

El tradicionalista afirma que "el decreto del 14 de diciembre de 1821 que creaba el banco de emisión" (Palma, 1964: 969) fue obra del ministro Bernardo de Monteagudo, pero sabemos, por Gamio Palacio, que el cabildo limeño tuvo decidida participación, ya que el ahora denominado ayuntamiento se enteró en la sesión del 27 de octubre de 1821 :

(...) del oficio del Ministerio de Hacienda a fin de que designe dos de sus miembros y dos vecinos "para que puedan dar su dictamen en la junta que ha de formarse sobre el modo de 
verificar un banco para la circulación de papel moneda”. El Cabildo eligió entre sus miembros al doctor Tiburcio José de la Hermoza y al doctor Miguel Antonio Vértiz y entre los vecinos a don Francisco Moreyra y a don Andrés Salazar. De conformidad con otro oficio del mismo Ministro pasado, el diecinueve de noviembre, el Ayuntamiento en la sesión celebrada el siguiente día, "procedió a elegir a veinticinco individuos de los hacendados principales de esta capital para que concurriesen a la sesión sobre el establecimiento del papel moneda. (Gamio, 1971: 446).

Hacemos esta acotación para demostrar que tanto el cabildo como la aristocracia titulada y no titulada, participó en la elaboración del proyecto aunque la tradición se enmarca en el verano del siguiente año de 1822 y versará sobre los vilipendios que una mujer de la plebe lanzara contra otro aristócrata limeño en el poder que no estuvo en las acciones preliminares para la creación del banco. Y retomando el tema del papel moneda afirma Paz Soldán que:

Tanto el Ministro de Hacienda D. Hipólito Unanue, como los encargados de formar el proyecto conocían todas estas dificultades; y sin embargo no se arredraron de llevarlo adelante; la necesidad de numerario era urgentísima y el deseo de satisfacerla les dio el valor para no detenerse ante los peligros de dificultades (...) Las operaciones del Banco consistían en emitir papel moneda como suplemento con el interés de dos por ciento al año; para pagar esos billetes o papel moneda, todas las oficinas del Estado recibían como dinero la mitad del valor en papel moneda y la otra mitad en dinero. Así mismo los particulares a quienes el tesoro tenía que pagar, estaban obligados a recibir la mitad en dinero y la otra en papel moneda, cualquiera que fuese la suma: pero todos sin distinción tenían que recibir o pagar de este modo las sumas que no excedieran de diez pesos. (Paz Soldán, Op.Cit: 296). 
Sobre la recepción del papel moneda por parte de la población limeña, Palma nos refiere en su tradición que:

El pueblo, a quien se le hacía muy cuesta arriba concebir que un retazo de papel puede reemplazar al metal acuñado, puso el grito en el séptimo cielo; y para acallarlo fue preciso que don Bernardo de Torre Tagle escupiese por el colmillo, mandando promulgar el $1^{\circ}$ de febrero un bando de espantamoscas, en el cual se determinaban las penas en que incurrían los que, en adelante, no recibiesen de buen grado los billetes de a dos y cuatro reales, únicos que se pusieron en circulación.

La medida produjo sus efectos. El pueblo refunfuñaba, y poniendo cara de vinagre agachó la cabeza y pasó por el aro; mientras que los hombres de palacio, satisfechos de su coraje para imponer la ley a la chusma, se pusieron, como dice la copla de coup de nez,

\author{
En la nariz el pulgar \\ y los demás en hilera, \\ y... perdonen la manera \\ de señalar.
}

Sin embargo, temió el gobierno que la mucha tirantez hiciera reventar la soga, y dio al pueblo una dedada de miel con el nombramiento de García del Río, quien marcharía a Londres para celebrar un empréstito, destinado a la amortización del papel y a sacar almas del purgatorio. (1964: 968-969).

\title{
La Lunareja y la desconfianza en el papel moneda
}

Palma nos narra los hechos que llevaron a castigar a una mujer de la plebe de nombre Gertrudis y con el alias de la Lunareja el 22 de febrero de 1822: 
(...) levantóse por la mañana en la Plaza mayor de Lima un tabladillo con un poste en el centro. A las dos de la tarde, y entre escolta de soldados, sacaron de la Pescadería a la Lunareja.

Un sayón o ministril la ató al poste y la cortó el pelo al rape. Durante la operación lloraba y se retorcía la infeliz, gritando:

-iPerdone mi amo Torretagle, que no lo haré más!

A lo que los mataperritos que rodeaban el tabladillo, azuzando al sayón que manejaba tijera y navaja, contestaban en coro:

Déle, maestro, déle, hasta que cante el miserere.

Y la Lunareja pensando que los muchachos aludían al estribillo del miz-miz, se puso a cantar, y como quien satisface cantando la palinodia:

\author{
iViva la patria \\ de los peruanos! \\ iMueran los godos \\ que son tiranos!
}

Pero la granujada era implacable, y comenzó a gritar con especial sonsonete:

iBoca dura, y pies de lana!

Déle maestro hasta mañana.

Terminada la rapadura, el sayón le puso a Gertrudis una canilla de muerto por mordaza, y hasta las cuatro de la tarde permaneció la pobre mujer expuesta a la vergüenza pública. 
Desde ese momento nadie se resistió a recibir el papel moneda. (Ibid: 970-971).

Pero ello no fue tan cierto, pues sabemos que la plebe no los aceptaba para el 14 de marzo a través de una comunicación dirigida por José Gonzales y Fuente, IV conde de Villar de Fuente, director del banco, al marqués de Torre Tagle (Rosas Siles, 1995: 521 ), como supremo delegado exponiendo:

Que el papel moneda que se ha puesto en circulación desde el $1^{\circ}$ del que rige (de febrero) se admitirá en el cambio sin quebranto alguno por el valor que representa por todos los habitantes del Estado. Está lejos de sancionar una derogación de los modos sancionados por el supremo gobierno en los capítulos $2^{\circ}$ y $3^{\circ}$; es una tácita confirmación de ellos y una expresa conminativa orden con que se concluye para sostener que el valor que representa el papel, sin alterar las condiciones con que deberá negociarse, jamás podrá ser alterado ni escusado su recibo en las proporciones establecidas. De otra suerte como el Bulgo (sic) lo ha entendido sería la ruina y destrucción de las casas de trato $(\ldots)^{1}$.

Hemos podido constatar con esta cita que, a los veinte días de haber sido castigada aquella mujer de la plebe, aún había problemas para que aquel gran sector de la población limeña aceptase los billetes. Prueba de ello también es el escrito del director del banco Conde de Villar de Fuente al ministro Hipólito Unanue (con fecha 12 de marzo de 1822), en el cual le comunica que todos los impresos de ocho reales y diez reales ${ }^{2}$ que se hallen por distribuir desde el $1^{\circ}$ del próximo abril lleven la rúbrica de los tres representantes del establecimiento: Andrés Salazar, Antonio Álvarez de Villar y del conde de Villar de Fuente, pero la

l AGN (1821). Sección OL, legajo $\mathrm{N}^{\circ} 48$, documento $\mathrm{N}^{\circ}$ 9, fls. 2r y 2v.

2 AGN (1821). Sección OL, legajo $N^{\circ} 48$, documento $N^{\circ} 5$, s/f. 
situación debió tornarse difícil pues este último fue removido del cargo por el supremo delegado dos días después (el 16 de marzo) y reemplazado por el conde de San Isidro.

Sobre la moza de rompe y raja, Palma acota: "Parece que mis paisanos aprovecharon de la lección en cabeza ajena, y no murmuraron más de las cosas gubernamentales" (Palma, 1964: 971). Pero, ello tal vez sería efectivo para los de su estamento, como lo era la plebe limeña, ya que observamos un comportamiento diferente por los limeños integrantes de la burocracia, pues cuatro meses y medio después del ejemplar castigo de Gertrudis la Lunareja, el 2 de julio, el conde de San Isidro le informaba al ministro de Hacienda don Hipólito Unanue lo siguiente:

Instruida esta dirección por un clamor general de no quererse recibir en varias oficinas del Estado el papel moneda ya por razón de entero de las ventas de algunos artículos como por donativo exigiéndose metálico sonante como ha sucedido últimamente en la Alta Cámara de Justicia con respecto de algunos individuos ${ }^{3}$.

Cámara que había reemplazado a la Real Audiencia, máximo organismo que otorgaba justicia en el antiguo virreinato.

Pero quién fue la Lunareja, esta mujer que osó enfrentarse al nuevo régimen. Palma nos la describe (1964: 970):

(...) una hembra, de las de navaja en la liga y pata de gallo en la cintura, conocida en el pueblo de Lima con el apodo de la Lunareja, y en la cual se realizaba al pie de la letra lo que dice el refrán:

3 AGN (1821). Sección OL, legajo $\mathrm{N}^{\circ}$ 48, documento $\mathrm{N}^{\circ}$ 29, s/f. 


\title{
Mujer lunareja \\ mala hasta vieja
}

Tenía la tal un tenducho o covachuela de zapatos en la calle de Judíos, bajo las gradas de la Catedral.

(...) Siempre que algún parroquiano llegaba al cuchitril de Gertrudis la Lunareja, en demanda de un par de zapatos de orejita, era cosa de taparse los oídos con algodones para no escucharla echar por la boca de espuerta que Dios la dio sapos, culebras y demás sucias alimañas. A pesar del riguroso bando conminatorio, la zapatera se negaba resueltamente a recibir papelitos, aderezando su negativa con una salsa parecida a ésta:

-Miren, miren al ladronazo de ño San Martín que, no contento con desnudar a la Virgen del Rosario, quiere llevarse la plata y dejarnos cartoncitos imprentados... iLa perra que lo pario al muy pu... chuelero!

Y la maldita, que era goda hasta la medula de los huesos, concluía su retahila de insultos contra el Protector cantando a grito herido una copla del miz-miz, bailecito en boga, en la cual se le zurraba la badana al supremo delegado marqués de Torre Tagle.

\author{
Peste de pericotes \\ hay en tu cuarto; \\ deja la puerta abierta, \\ yo seré el gato. \\ iMuera la patria! \\ iMuera el marqués! \\ iQue viva España! \\ iQue viva el rey!
}


Es importante señalar la acotación muy válida del tradicionista acerca de las circunstancias de la guerra civil que se vivía en el interior del aún virreinato peruano, desde el sur de Ica hasta Tucumán. Nos dice:

¡Canario! El cantorcito no podía ser más subversivo en aquellos días en que la palabra rey quedó tan proscrita del lenguaje, que se desbautizó al peje-rey para llamarlo pejepatria, y al pavo real se lo confirmó con el nombre de pavo nacional" (Ibid: 970).

El tradicionista sigue contándonos como se comportaba aquella mujer:

Los descontentos que a la sazón pululaban aplaudían las insolencias y obscenidades de la Lunareja, que propiedad de pequeños y cobardes es festejar la inmundicia que los maldicientes escupen sobre las espaldas de los que están en el poder. Así envalentonada la zapatera, acrecía de hora en hora en atrevimiento, haciendo huesillo a los agentes de policía, que, de vez en cuando, la amonestaban para que no escandalizara al patriota y honesto vecindario. (Ibidem).

Sabemos que, desde el 3 de Agosto de 1821, el coronel José de la Riva Agüero y Sánchez Boquete (Tauro, 2001, vol. 14: 2262) era presidente del departamento de Lima, cargo equivalente al intendente virreinal, y era quien debía de resolver aquella incómoda situación; pero como el marqués de Torre Tagle se encargaba del Poder Ejecutivo del Protectorado como supremo delegado desde el 20 de enero de 1822 hasta 21 de Agosto de 1822 (Tauro, 2001, vol.16: 2580), él era la máxima jerarquía del Estado a quien "la Lunareja" insultaba, y bien dice Palma (1964: 970):

Impuesta de todo la autoridad, vaciló mucho el desgraciado Torretagle para poner coto al escándalo. Repugnaba a su 
caballerosidad el tener que aplicar las penas del bando en una mujer.

El alcalde del barrio recibió al fin la orden de acercarse a la Lunareja y reprenderla; pero ésta que, como hemos dicho, tenía lengua de barbero afilada y cortadora, acogió al representante de la autoridad con un aluvión de dicterios tales, que al buen alcalde se le subió la mostaza a las narices, y llamando cuatro soldados hizo conducir, amarrada y casi arrastrando, a la procaz zapatera a un calabozo de la cárcel de la Pescadería. Lo menos que le dijo a su merced fue:

\author{
Usía y mi marido \\ van a Linares \\ a comprar cuatro bueyes: \\ vendrán tres pares.
}

\begin{abstract}
A pesar del castigo ejemplar que se le dio a la Lunareja, la situación no mejoró con respecto a la aceptación del papel moneda por parte del pueblo limeño. Paz Soldán afirmó que para julio de 1822:
\end{abstract}

Poco importaba que el Banco hiciera sus amortizaciones periódicas; su crédito no aumentaba y fue preciso estimularlo admitiendo la mitad en papel y la otra en dinero, toda clase de deudas al Estado cualquiera que fuese su origen, no habiéndose pactado muy expresamente lo contrario (16 de julio) pero nada de esto bastaba para inspirar confianza al pueblo que recordaba los males y perdidas que sufría y las vejaciones y violencias que se empleaba contra los que no querían recibir el papel como moneda; y la exacerbación eran tan pronunciada que el Gobierno conoció el peligro de un alzamiento. (1971: 297). 


\section{Reflexiones finales}

Cuando ya se acababa el régimen del Protectorado y faltaban pocos días para la partida del Perú del general San Martín, Paz Soldán explica que el Congreso Constituyente resolvió el 18 de noviembre de 1822 "extinguir el papel moneda, mandando acuñar moneda de cobre con un valor representativo de plata (Paz Soldán, 1971: 297) y que el 5 de diciembre de 1822 el director del banco en una nota de fecha de ayer (4) remitida por Francisco Valdivieso, secretario de Estado y Hacienda, ordenaba "se impriman ciento un mil ciento cuarenta pesos en billetes de dos reales con que se completen quinientos mil pesos que han de circular y se amortizarán con igual cantidad de cobre que se está amonedando y luego de que esté concluida la impresión le noticiará esta dirección $(\ldots)^{4}$. Al final nuestro tradicionista acertó en su aseveración: el bando del $1^{\circ}$ de febrero de 1822 buscando la aceptación de los billetes fue de espantamoscas a pesar de no haber encontrado ningún documento sobre aquel bando y la Lunareja; creemos que el tradicionista vio los documentos y estos probablemente desaparecieron en el incendio de la Biblioteca Nacional de 1943. Hemos podido demostrar que no hubo una actitud receptiva hacia los billetes de papel por parte de la población y hasta de algunas autoridades.

\section{Bibliografía}

AGN (1821) Sección OL, legajo $N^{\circ} 48$, documento $N^{\circ}$ 5, s/f.

Sección OL, legajo $\mathrm{N}^{\mathrm{o}} 48$, documento $\mathrm{N}^{\circ}$ 9, fls. 2ry $2 \mathrm{v}$.

Sección OL, legajo $\mathrm{N}^{\circ} 48$, documento $\mathrm{N}^{\circ} 29$, s/f.

Sección OL, legajo $N^{o} 48$, documento $N^{0} 44$, s/f.

4 AGN (1821). Sección OL, legajo $\mathrm{N}^{\circ} 48$, documento $\mathrm{N}^{\circ} 44$, s/f. 
Palma, R. (1964). Tradiciones Peruanas. Barcelona: Montaner y Simón.

Paz Soldán, M. F. (1971). El Perú y su independencia. Antología: período 1819-1822. vol. II. Lima: Instituto "Libertador Ramón Castilla" y Centro de Estudios Histórico-Militares del Perú,

Revista del Instituto Peruano de Investigaciones Genealógicas No 21 (1995). Lima, Instituto Peruano de Investigaciones Genealógicas.

Recibido el 29 de noviembre del 2017 Aceptado el 19 de enero del 2018 